
ISSN : 2615-1995, E-ISSN : 2615-0654

J. Madani., Vol. 2, No. 1, Maret 2019 (147 - 161)

(C)2018 Lembaga Kajian Demokrasi

MADANI

dan Pemberdayaan Masyarakat (LKD-PM)

\title{
PENGARUH EKUITAS MEREK TERHADAP KEPUTUSAN PEMBELIAN HANDPHONE XIAOMI (STUDI KASUS KOMUNITAS MI FANS JAKARTA DAN DEPOK)
}

\author{
Syamruddin \\ Fakultas Ekonomi, Universitas Pamulang \\ dosen01343@unpam.ac.id \\ Fhadilah Nur Hakim \\ Fakultas Ekonomi, Universitas Pamulange \\ fhadilahnurhakim@gmail.com
}

\begin{abstract}
Abstrak
Penelitian dilakukan pada Komunitas MI Fans Jakarta dan Depok, yang merupakan bentuk dari Fans Xiaomi di Tanah Air. Kendati Brand Xiaomi baru hadir di Indonesia, namun kelompok penggemar produk ini telah terbentuk. Dalam penelitian ini terdapat dua variabel yaitu Variabel X (Ekuitas Merek) dan Variabel Y (Keputusan Pembelian). Penelitian bertujuan untuk mengetahui Ekuitas Merek pada Komunitas MI Fans Jakarta dan Depok dan pengaruh Keputusan Pembelian terhadap Ekuitas Merek pada Komunitas MI Fans Jakarta dan Depok. Metode yang digunakan adalah penelitian deskriptif dengan analisa data kuantitatif. Selain itu analisis untuk membahas identifikasi masalah bagaimana Ekuitas Merek pada Komunitas MI Fans Jakarta dan Depok dan Keputusan Pembelian pada Komunitas MI Fans Jarkarta dan Depok. Selanjutnya verifikatif analisis untuk membahas identifikasi masalah seberapa besar pengaruh Ekuitas Merek terhadap Keputusan Pembelian pada Komunitas MI Fans Jakarta dan Depok. Data yang digunakan dalam penelitian ini adalah data primer dan data sekunder yang dikumpulkan melalui observasi, angket (kuesioner), dan studi kepustakaan. Adapun hipotesis dari penelitian ini adalah adanya pengaruh antara Ekuitas Merek terhadap Keputusan Pembelian pada Komunitas MI Fans Jakarta dan Depok. Untuk mengukur seberapa besar pengaruh variabel tersebut digunakan regresi linier sederhana dan koefisien determinasi. Berdasarkan hasil analisis data dengan menggunakan metode statistik yaitu regresi linier sederhana, diperoleh nilai koefisien determinasi (KD) sebesar 17,09\% dengan nilai koefisien korelasi sebesar 0,41346. Berdasarkan hasil tersebut dapat disimpulkan bahwa Ekuitas Merek berpengaruh terhadap Keputusan Pembelian pada Komunitas MI Fans Jakarta dan Depok.
\end{abstract}

Kata Kunci : Ekuitas Merek, Keputusan Pembelian, Handphone Xiaomi, Komunitas MI

\begin{abstract}
The study was conducted at the MI Community of Jakarta and Depok Fans, which is a form of Xiaomi Fans in the country. Although the new Xiaomi Brand is present in Indonesia, but a fan group of this product has been formed. In this study there are two variables, namely Variable X (Brand Equity) and Variable Y (Purchase Decision). The study aims to determine Brand Equity in the Community of MI Jakarta and Depok Fans and the influence of Purchasing Decision on Brand Equity in the MI Community of Jakarta and Depok Fans. The method used is descriptive research with quantitative data analysis. In addition, the analysis is to discuss the identification of problems of Brand Equity in the Community of MI Jakarta and Depok Fans and Purchase Decisions in the MI Fans of Jarkarta and Depok. Next is the verification of the analysis to discuss the identification of the problem of how much influence Brand Equity has on Purchasing Decisions in the MI Community of Jakarta and Depok Fans. The data used in this study are primary data and secondary data collected through observation, questionnaire (questionnaire), and literature study. The hypothesis of this study is that there is an influence between Brand Equity on Purchasing Decisions in the MI Community of Jakarta and Depok Fans. To measure
\end{abstract}


how much influence these variables use simple linear regression and coefficient of determination. Based on the results of data analysis using statistical methods, namely simple linear regression, obtained the coefficient of determination (KD) of $17.09 \%$ with a correlation coefficient of 0.41346 . Based on these results it can be concluded that Brand Equity has an effect on Purchasing Decisions in the MI Community of Jakarta and Depok Fans.

Keywords : Brand Equity, Purchase Decision, Xiaomi Mobile, MI Community

\section{PENDAHULUAN}

\section{Latar Belakang}

Perkembangan industri telekomunikasi, khususnya teknologi mobile semakin pesat. Hal ini membuat para pemain di industri ini harus bekerja keras agar produk-produk yang mereka tawarkan dapat diterima di pasar. Selain itu konsumen juga akan senantiasa tertarik terhadap produk-produk yang ditawarkan.

Pesatnya perkembangan smartphone yang dikemas dalam teknologi yang sangat canggih menjadikan persaingan bisnis juga sangat ketat. Salah satunya adalah kehadiran smartphone asal negeri "Tirai Bambu" China, yaitu merek Redmi atau produknya yang lebih dikenal dengan sebutan Xiaomi. Walaupun sebagai pendatang baru, merek ini tentunya sudah tidak asing di telinga konsumen Indonesia karena menyasar pengguna smartphone kelas menengah ke bawah.

Salah satu strategi yang dibenamkan oleh produsen Xiaomi adalah dengan cara memperkuat merek produk-produk mereka di pasar. Dengan demikian akan terbangun ekuitas merek yang sangat kuat di benak pelanggan terhadap smartphone Xiaomi. Sehingga memudahkan produsen untuk memperbesar pangsa pasarnya di Indonesia.

Kendati produk Xiaomi belum bisa menyaingi atau menggeser Samsung dari Rangking 1 penjualan smartphone di Indonesia, namun Xiaomi telah dapat membentuk konsumen yang fanatik. Hal itu terlihat dari munculnya komunitas-komunitas Xiaomi di Tanah Air. Salah satunya, Komunitas Xiaomi Jakarta dan Depok, yang merupakan bentuk dari fans Xiaomi.

Kendati baru beberapa saat saja produk dengan brand Xiaomi hadir di Indonesia, kelompok penggemar produk ini pun telah terbentuk. Ini merupakan salah satu keunggulan dari produk Redmi yang merupakan produk smartphone dengan komunitas yang banyak.

MI Fans. Demikian sebutan dari komunitas Xiaomi Jakarta dan Depok ini. Komunitas ini berisikan kumpulan pengguna dari smartphone produk Xiaomi. Kegiatan yang dilakukan oleh komunitas ini sangat bervariasi. Salah satu kegiatan menarik yang mereka lakukan adalah gathering antar muka smartphone.

Mengingat ekuitas merek merupakan faktor yang dapat menjadi pertimbangan dalam keputusan pembelian handphone Xiaomi, maka penulis tertarik untuk melakukan penelitian lebih dalam dengan judul : "PENGARUH EKUITAS MEREK TERHADAP KEPUTUAN PEMBELIAN HANDPHONE XIAOMI (STUDI KASUS PADA KOMUNITAS MI FANS JAKARTA DAN DEPOK)".

\section{Pembatasan Masalah}

Dengan keterbatasan peneliti serta agar lebih mudah dipahami dan dimengerti, maka dalam penelitian ini penulis memberikan batasan-batasan yang diteliti. Penelitian ini difokuskan pada produk smartphone merek Xiaomi. Adapun hal yang diteliti adalah mengenai ekuitas merek dan pengaruhnya terhadap keputusan konsumen untuk membeli handphone Xiaomi. Sedangkan cara yang dilakukan adalah dengan penyebaran kuesioner kepada komunitas MI Fans yang ada di Jakarta dan Depok yang merupakan konsumen fanatik handphone Xiaomi.

\section{Perumusan Masalah}

Berdasarkan latar belakang dan pembatasan masalah di atas, maka untuk mencegah terjadinya kerancuan dalam pembahasan, maka penulis memberikan suatu perumusan masalah sebagai berikut :

1. Apakah terdapat pengaruh secara simultan ekuitas merek terhadap keputusan pembelian handphone Xiaomi.

2. Apakah terdapat pengaruh secara parsial ekuitas merek terhadap keputusan pembelian handphone Xiaomi.

3. Berapa besar pengaruh Ekuitas Merek terhadap keputusan pembelian terhadap handphone Xiaomi.

\section{Tujuan Penelitian}

Adapun tujuan penelitian ini adalah :

a. Untuk mengetahui pengaruh ekuitas merek terhadap keputusan pembelian handphone Xiaomi secara simultan.

b. Untuk mengetahui pengaruh ekuits merek terhadap keputusan pembelian handphone Xiaomi secara parsial.

\section{Tinjauan Teoritik \\ Ekuitas Merek}

Ekuitas merek (brand equity) adalah seperangkat asosiasi dan perilaku yang dimilki oleh pelanggan merek, anggota saluran distribusi, dan perusahan yang memungkinkan suatu me- 
rek mendapatkan kekuatan, daya tahan, dan keunggulan yang dapat membedakan dengan merek pesaing sebagaimana dikemukakan oleh Astuti dan Cahyadi (2007).

Kotler dan Keller (2007), mendefinisikan ekuitas merek sebagai nilai tambah yang diberikan kepada produk dan jasa. Nilai ini bisa mencerminkan dalam bentuk cara seorang konsumen dalam berpikir, merasa, dan bertindak terhadap merek, harga pangsa pasar serta profitabilitas yang dimiliki perusahaan.

Knapp (2001), mendifinisikan ekuitas merek sebagai totalitas dari persepsi merek, mencakup kualitas relatif dari produk dan jasa, kinerja keuangan, loyalitas pelanggan, kepuasan, dan keseluruhan penghargaan terhadap merek.

Durianto dan kawan-kawan (2004), menjelaskan, ekuitas merek dapat memberikan nilai bagi perusahaan, yaitu :

a. Ekuitas merek yang kuat dapat membantu perusahaan dalam upaya menarik minat calon konsumen serta upaya untuk menjalin hubungan yang baik dengan para pelanggan dan dapat menghilangkan keraguan konsumen terhadap kualitas merek.

b. Seluruh elemen ekuitas merek dapat mempengaruhi keputusan pembelian konsumen karena ekuitas merek yang kuat akan mengurangi keinginan konsumen untuk berpindah ke merek lain.

c. Konsumen yang memiliki loyalitas tinggi terhadap suaru merek tidak akan mudah untuk berpindah, walaupun pesaing telah melakukan inovasi produk.

d. Asosiasi merek akan berguna bagi perusahaan untuk melakukan evaluasi atas keputusan strategi perluasan merek.

e. Perusahaan yang memiliki ekuitas merek yang kuat dapat menentukan harga premium serta mengurangi ketergantungan perusahaan terhadap promosi.

f. Perusahaan yang memiliki ekuitas merek yang kuat dapat menghemat pengeluaran biaya pada saat perusahaan memutuskan untuk melakukan perluasan merek.

g. Ekuitas merek yang kuat akan menciptakan loyalitas saluran distribusi yang akan meningkatkan jumlah penjualan perusahaan.

Keller (2009) menyatakan bahwa ekuitas merek atau brand equity berasal dari konsumen, sehingga seringkali disebut sebagai customerbased brand equity (CBBE). Oleh karena itu CBBE muncul ketika konsumen memiliki tingkat kesadaran dan keakraban yang tinggi dengan sebuah brand dan memiliki asosiasi yang kuat dan unik terhadap brand tersebut dalam pikirannya.

Ada dua sumber dari CBBE, yaitu :

- Brand Awareness
Brand awareness terdiri dari brand recognition dan brand recall performance. Brand recognition adalah kemampuan konsumen untuk mengenali sebuah merek sebelum di berikan penjelasan. Brand recall performance adalah kemampuan konsumen untuk memilih brand dari ingatannya ketika diberikan kategori produk, atau kebutuhan yang dipenuhi oleh kategori produk tersebut.

- Brand Image

Menciptakan sebuah brand image yang positif membutuhakan program marketing yang memiliki asosiasi brand yang kuat (strength of brand association). Asosiasi brand yang menguntungkan (favourability of brand association) dan asosiasi brand yang unik (uniqueness of brand Brand Association).

- Asosiasi brand yang kuat (favorability of brand association)

Semakin dalam seseorang berpikir tentang informasi produk dan menghubungkannya dengan pengetahuan tentang brand tersebut, maka semakin kuat asosiasi brand yang terjadi. Konsumen membentuk keyakinan tentang brand attributes dan brand benefits dengan cara yang berbeda. Brand attributes adalah fitur deskriptif yang menjadi ciri sebuah produk atau jasa. Brand benefits adalah nilai dan makna pribadi yang dilekatkan konsumen pada atribut sebuah produk atau jasa.

- Asosiasi brand yang menguntungkan (favourability of brand association)

Asosiasi yang menguntungkan bagi sebuah brand adalah asosiasi yang diinginkan oleh konsumen (desirability) dan disampaikan oleh produk (deliverability). Desirability tergantung pada faktor, yaitu seberapa relevan, seberapa khas, dan seberapa percaya konsumen dengan asosiasi brand. Deliverability juga tergantung pada tiga faktor, yaitu kemampuan sebenarnya atau kemampuan potensional dari produk, kemungkinan menyampaikan kemampuan tersebut saat ini atau di masa depan, dan kesinambungan kemampuan sebenarnya dan kemampuan yang dikomunikasikan.

- Asosiasi brand yang unik (uniqusness of brand association)

Keunikan biasanya diperoleh dari perbandingan dengan competitor. Perbandingan ini dapat didasarkan pada atribut atau keuntungan yang berhubungan atau tidak berhubungan dengan produk. Selanjutnya, terciptanya ekuitas merek yang 
signifikan mengharuskan kita mencapai puncak atau titik tertinggi piramida merek, yang hanya terjadi jika kotak bangunan yang tepat terpasang pada tempatnya. Indikator ekuitas merek menurut Kotler \& Keller (2009:267-268) dalam model resonasi merek adalah :

a. Keutamaan merek adalah seberapa sering dan seberapa mudah pelanggan memikirkan merek dalam berbagai situasi pembelian atau konsumsi.

b. Kinerja merek adalah seberapa baik produk atau jasa memenuhi kebutuhan fungsional pelanggan.

c. Pencitraan merek adalah menggambarkan sifat ekstrinsik produk atau jasa, termasuk cara di mana merek berusaha memenuhi kebutuhan psikologis atau sosial pelanggan.

d. Penilaian merek adalah berfokus pada pendapat dan evaluasi pribadi pelanggan sendiri.

e. Perasaan merek adalah respons dan reaksi emosional pelanggan terhadap merek.

f. Resonasi merek adalah mengacu pada sifat hubungan yang dimiliki pelanggan dengan merek dan sejauh mana mereka merasa "sinkron" dengan merek.

\section{Keputusan Pembelian}

Menurut Kotler (2012:166) keputusan pembelian adalah proses keputusan pembeli yang terdiri dari lima tahap yang dilakukan oleh seorang konsumen sebelum sampai pada keputusan pembelian dan selanjutnya paska pembelian.

Keputusan pembelian yang diungkapkan Kotler dan Keller (2102:170) : "in the evaluation stage, the consumers from preferences among the brans in the choice set ang may also from an intention to buy the most preferred brand."

Dapat diartikan keputusan pembelian merupakan evaluasi, konsumen dari preferensi di antara merek pada set pilihan dan mungkin juga dari niat untuk membeli merek yang paling disukai.

Sejalan dengan pengertian tersebut, Kotler dan Armstrong (2102:128) menyatakan bahwa "consumer buyer behavior refers to the buying behavior of final consumers individuals and households who buy goods and services for personal consumption". Berdasarkan definisi tersebut dapat dikatakan bahwa perilaku konsumen selalu melihat perilaku dari tiap individu, rumah tangga ataupun organisasi tentang bagaimana mereka berproses sebelum memutuskan untuk melakukan pembelian, serta tindakannya setelah memperoleh dan mengkonsumsi produk, jasa atau ide.

Terdapat empat jenis proses pembelian konsumen, yaitu pengambilan keputusan yang kompleks, pengambilan keputusan yang terbatas, kesetiaan pada merek, dan inertia. Pembelian yang memiliki keterlibatan rendah, menghasilkan perilaku pengambilan keputusan yang terbatas.

Konsumen kadang-kadang melakukan pengambilan keputusan, walaupun memiliki keterlibatan yang rendah terhadap produk. Konsumen kurang memahami kategori produk, pencarian informasi, dan evaluasinya lebih terbatas dibandingkan dengan proses yang kompleks.

Selanjutnya ada banyak model perilaku pembeli yang diutarakan oleh beberapa pakar marketing manajemen. Pada dasarnya model yang mereka kemukakan kurang lebih adalah sama.

Salah satu model yang terkenal adalah "model of buyer behavior" oleh Kotler (2012:45). Keputusan untuk membeli yang diambil oleh pembeli sebenarnya merupakan kumpulan dari sejumlah keputusan.

Setiap keputusan membeli mempunyai satu struktur sebanyak tujuh komponen. Komponenkomponen tersebut dalam kaitannya dengan pembelian sebuah produk misalnya adalah produk elektronik berupa radio sebagaimana yang dikemukakan Swasth (2010:102), yakni :

a. Keputusan tentang jenis produk konsumen dapat mengambil keputusan untuk membeli sebuah radio atau menggunakan uangnya untuk tujuan lain. Dalam hal ini perusahaan harus memusatkan perhatiannya kepada orang-orang yang berminat membeli radio serta alternatif lain yang mereka pertimbangkan.

b. Keputusan tentang bentuk produk konsumen dapat mengambil keputusan untuk membeli bentuk radio tertentu. Keputusan tersebut menyangkut pola ukuran, mutu suara, corak, dan sebagainya. Dalam hal ini perusahaan harus melakukan riset pemasaran untuk mengetahui kesukaan konsumen tentang produk yang diinginkan agar dapat memaksimumkan daya tarik mereknya.

c. Keputusan tentang merek konsumen harus mengambil keputusan tantang merek mana yang akan dibeli. Setiap merek memiliki perbedaan-perbedaan tersendiri. Dalam hal ini perusahaan harus mengetahui bagaimana konsumen memilih sebuah merek.

d. Keputusan tentang penjualnya, konsumen harus mengambil keputusan di mana radio tersebut akan dibeli. Apakah pada toko serba ada, toko alat-alat listrik, toko khusus radio, atau toko lain. Dalam hal ini produsen, pedagang besar, dan pengecer harus mengetahui bagaimana konsumen memilih penjual tertentu.

e. Keputusan tentang jumlah produk konsumen dapat mengambil keputusan tentang seberapa banyak produk yang akan dibelinya 
pada suatu saat. Pembelian yang dilakukan mungkin lebih dari satu unit. Dalam hal ini perusahaan harus mempersiapkan banyaknya produk sesuai dengan keinginan yang berbeda-beda dari para pembeli.

f. Keputusan tentang waktu pembelian konsumen dapat mengambil keputusan tentang kapan ia harus melakukan pembelian. Masalah ini akan menyangkut tersedianya uang untuk membeli radio. Oleh karena itu perusahaan harus mengetahui faktor-faktor yang mempengaruhi keputusan konsumen dalam penentuan waktu pembelian. Dengan demikian perusahaan dapat mengatur waktu produksi dan kegiatan pemasarannya.

g. Keputusan tentang cara pembayaran konsumen harus mengambil keputusan tentang metode atau cara pembayaran produk yang dibeli, apakah secara tunai atau dengan cicilan. Keputusan tersebut akan mempengaruhi keputusan tentang penjual dan jumlah pembelinya. Dalam hal ini perusahaan harus mengetahui keinginan pembeli terhadap cara pembayaran.

Menurut Hahn (2002:69), ada tiga aktivitas yang berlangsung dalam proses keputusan pembelian oleh konsumen yaitu :

1. Rutinitas konsumen dalam melakukan pembelian.

2. Kualitas yang di peroleh dari suatu keputusan pembelian.

3. Komitmen atau loyalitas konsumen yang sudah biasa beli dengan produk asing.

Sebuah keputusan tidak mungkin dapat dibentuk begitu saja. Harus ada tahapan-tahapan yang mendahului dalam proses pembuatan keputusan tersebut agar tidak terjadi penyesalan dikemudian hari.

Konsumen memiliki model dalam mengambil keputusan untuk melakukan pembelian. Perusahaan perlu mengidentifikasi model konsumen dalam keputusan pembelian untuk me ngenali konsumen tersebut. Shiffman dan Kanuk (2010:480-482) memperkenalkan model konsumen yang mengacu pada tentang bagaimana konsumen berprilaku berdasarkan empat pandangan yaitu:

a. Economic view (pandangan ekonomis), yaitu konsumen digolongkan sebagai seorang yang membuat keputusan.

b. Passive view (pandangan pasif), yaitu konsumen yang digambarkan sebagai konsumen yang patuh terhadap keinginan dan promosi dari pemasar.

c. Cognitive view (pandangan kognitif), yaitu model yang fokus pada proses konsumen dalam mencari dan mengevaluasi informasi mengenai merek dan toko eceran. d. Emotional view (pandangan emosional), yaitu konsumen yang pada saat melakukan pembelian cenderung memperhatikan dan mencari informasi dengan memperhatikan perasaan dan suasana hatinya.

Sementara itu menurut Kotler (2012:166), faktor-faktor yang mempengaruhi keputusan pembelian terdiri dari :

a. Pengenalan masalah

Pembeli menyadari suatu perbedaan antara keadaan sebenarnya dan keadaan yang diinginkan. Tahap ini sedikit banyak dipengaruhi oleh bagaimana pengetahuan konsumen akan pembelian. Dimensi dasar dari pengenalan kebutuhan melibatkan informasi berkenaan dengan keputusan tentang di mana produk tersebut harus dibeli dan kapan pembelian harus terjadi.

b. Pencarian informasi

Seorang konsumen yang mulai tertarik dengan minatnya mungkin akan atau mungkin tidak mencari informasi. Konsumen mungkin hanya meningkatkan perhatian atau mungkin aktif mencari informasi. Pada tahap ini seorang yang telah tertarik akan suatu produk mungkin akan mencari lebih banyak informasi. Jika dorongan konsumen begitu kuat dan produk yang memuaskan berada dalam jangkauan, konsumen kemungkinan besar akan melakukan pembelian. Namun demikian jika tidak, konsumen kemungkinan menyimpan kebutuhannya dalam ingatan atau melakukan pencarian informasi yang berkaitan dengan kebutuhan itu.

c. Evaluasi alternatif

Konsumen harus melakukan penilaian tentang beberapa alternatif yang tersedia. Tahap dalam proses pengambilan keputusan pembelian di mana konsumen menggunakan informasi untuk mengevaluasi merek-merek alternatif dalam satu susunan pilihan.

d. Keputusan pembelian

Pengambilan keputusan apakah konsumen memutuskan membeli atau tidak. Tahap dalam proses pengambilan keputusan pembeli di mana konsumen benar-benar membeli produk.

e. Perilaku paska pembelian

Konsumen akan mengalami beberapa tingkat kepuasan atau tidak merasa puas sama sekali. Tahap dalam proses pengambilan keputusan pembeli di mana konsumen mengambil tindakan lebih lanjut setelah membeli berdasarkan kepuasan yang mereka rasakan.

\section{Hipotesis Penelitian}

Hipotesis Menurut Mudrajad Kuncoro, Ph.D 
(2003:47) adalah suatu penjelasan sementara tentang perilaku, fenomena atau keadaan yang telah terjadi atau akan terjadi. Karena sifatnya sementara, maka perlu dibuktikan kebenaranya melalui data empirik yang terkumpul. Hipotesis dalam penelitian ini adalah harapan yang dinyatakan oleh peneliti mengenai hubungan antara variabel-variabel di dalam masalah penelitian tersebut.

Adapun hipotesis dalam penelitian ini adalah:

1. $\mathrm{H}_{0}$ : Tidak terdapat pengaruh ekuitas merek terhadap keputusan pembelian handphone Xiaomi.

2. $\mathrm{H}_{\mathrm{a}}$ : Terdapat pengaruh ekuitas merek terhadap keputusan pembelian handphone Xiaomi.

\section{METODE}

\section{Tempat dan Waktu Penelitian}

Penelitian ini dilaksanakan pada komunitas MI fans Jakarta dan Depok. Penelitian ini dilaksanakan selama 3 (tiga) bulan terhitung mulai Maret sampai dengan Mei 2018.

\section{Populasi dan Sampel}

Adapun populasi dalam penelitian ini adalah anggota komunitas MI Fans Jakarta dan Depok berjumlah 2.500 orang. Sedangkan teknik yang digunakan dalam penarikan sampel ini adalah tehnik simple random sampling yakni tehnik penentuan sampel dan populasi dilakukan secara acak tanpa memperhatikan strata yang ada dalam populasi. Jumlah sampel diambil dalam penelitian ini ditentukan dengan menggunakan rumus Slovin. Jumlah responden yang dijadikan sampel sebanyak 96 reponden.

\section{Variabel Penelitian}

Dalam penelitian ada dua variabel penelitian yaitu variabel independen atau bebas dan variabel dependen atau terikat. Adapun variabel independen adalah Ekuitas Merek yang dilambangkan dengan $\mathrm{X}$ dan variabel dependen adalah Keputusan Pembelian yang dilambangkan dengan $\mathrm{Y}$.

\section{Defenisi Operasional Variabel}

Pengertian operasional variabel di sini diuraikan menjadi indikator empiris yang meliputi :

1. Ekuitas Merek (X)

Variabel ini diukur melalui indikator Keutamaan Merek, Kinerja Merek, Pencitraan Merek, Penilaian Merek, Perasaan Merek, dan Resonasi Merek.

2. Keputusan Pembelian (Y)

Variabel ini diukur melalui indikator Pengenalan Masalah, Pencarian Informasi, Evaluasi Alternatif, Keputusan Pembelian, dan Perilaku Pasca Pembelian.

\section{Teknik Pengumpulan Data}

1. Observasi

2. Kuesioner

3. Dokumentasi

3. Studi Pustaka

\section{Metode Analisis Data}

Analisis Kualitas Data

1. Uji Validitas

2. Uji Reliabilitas

Analisis Data

1. Uji Koefisien Korelasi

2. Analisis Koefisien Determinasi

3. Uji Regresi Linier Sederhana

4. Uji Signifikan

\section{HASIL dan PEMBAHASAN}

\section{Analisis Deskriptif Variabel Penelitian}

1. Variabel Ekuitas Merek (X)

Berdasarkan hasil jawaban responden untuk pernyataan terhadap variabel ekuitas merek (X) jumlah seluruh hasil pernyataan adalah = $778+494+128+40+0=1440$ dengan perhitungan persentase sebagai berikut :

$$
\begin{aligned}
& \mathrm{SS}=\frac{778 \times 100 \%}{1440}=54 \% \\
& \mathrm{~S}=\frac{494 \times 100 \%}{1440}=34 \% \\
& \mathrm{RR}=\frac{128 \times 100 \%}{1440}=9 \% \\
& \mathrm{TS}=\frac{40 \times 100 \%}{1440}=3 \% \\
& \mathrm{STS}=\frac{0 \times 100 \%}{1440}=0 \%
\end{aligned}
$$

Dari keterangan persentase terhadap ekuitas merek pada Komunitas MI Fans Jakarta dan Depok mendapat respon cukup baik. Hal ini berdasarkan hasil responden yang berjumlah 96 orang dengan 15 pernyataan dengan rincian persentase yaitu responden yang menjawab Sangat Setuju (SS) sebanyak 778 atau 54\%, yang menjawab Setuju (S) sebanyak 494 atau 34\%, yang menjawab Ragu-Ragu (RR) sebanyak 128 atau 9\%, yang menjawab Tidak Setuju (TS) sebanyak 40 atau 3\%, yang menjawab Sangat Tidak Setuju (STS) tidak ada atau $0 \%$.

Sesuai data yang terkumpul dari olahan hasil kuesioner menunjukkan bahwa ekuitas merek pada Komunitas MI Fans Jakarta dan Depok sudah tergolong baik karena dilihat dari responden yang menjawab Sangat Setuju (SS) sebanyak 778 atau $54 \%$.

\section{Variabel Keputusan Pembelian (Y)}

Dari hasil jawaban responden untuk pernyataan terhadap variabel keputusan pembelian 
(Y) jumlah seluruh hasil pernyataan adalah = $673+497+199+71+0=1440$ dengan perhitungan persentase sebagai berikut :

$$
\begin{aligned}
& \mathrm{SS}=\frac{673 \times 100 \%}{1440}=47 \% \\
& \mathrm{~S}=\frac{497 \times 100 \%}{1440}=35 \% \\
& \mathrm{RR}=\frac{199 \times 100 \%}{1440}=14 \% \\
& \mathrm{TS}=\frac{71 \times 100 \%}{1440}=5 \% \\
& \mathrm{STS}=\frac{\mathrm{oX} 100 \%}{500}=0 \%
\end{aligned}
$$

Dari keterangan persentase terhadap keputusan pembelian pada Komunitas MI Fans Jakarta Dan Depok mendapat respon cukup baik. Hal ini berdasarkan hasil responden yang berjumlah 96 orang dengan 15 pernyataan dengan rincian persentase yaitu responden yang menjawab Sangat Setuju (SS) sebanyak 673 atau 47\%, yang menjawab Setuju (S) sebanyak 497 atau 35\%, yang menjawab Ragu-Ragu (RR) sebanyak 199 atau 14\%, yang menjawab Tidak Setuju (TS) sebanyak 71 atau 5\%, yang menjawab Sangat Tidak Setuju (STS) tidak ada atau $0 \%$.

Sesuai data yang terkumpul dari olahan hasil kuesioner menunjukkan bahwa keputusan pembelian yang ada pada Komunitas MI Fans Jakarta Dan Depok sudah tergolong baik karena dilihat dari responden yang menjawab Sangat Setuju (SS) sebanyak 673 atau $47 \%$.

\section{Hasil Analisis Data}

1. Hasil Uji Validitas

a. Variabel X (Ekuitas Merek)

Berdasarkan data olahan diketahui :

$$
\begin{aligned}
\mathrm{N} & =96 \\
\sum \mathrm{Xi} & =402 \\
\sum \mathrm{Xt} & =6.330 \\
\sum \mathrm{Xi} . \mathrm{Xt} & =26.587 \\
\sum \mathrm{Xi}^{2} & =1.752 \\
\sum \mathrm{Xt}^{2} & =418.980
\end{aligned}
$$

$$
r_{x y}=\frac{n \cdot\left(\sum X X t\right)-\left(\sum X\right) \cdot\left(\sum X t\right)}{\sqrt{\left(n \cdot \sum X^{2}-\left(\sum X\right)^{2} \cdot\left(n \cdot \sum X t^{2}-\left(\sum X t\right)^{2}\right)\right.}}
$$

$r_{x y}=\frac{n \cdot\left(\sum X x t\right)-\left(\sum X\right) \cdot\left(\sum x t\right)}{\sqrt{\left(n \cdot \sum X^{2}-\left(\sum X\right)^{2} \cdot\left(n \cdot \sum X t^{2}-\left(\sum X t\right)^{2}\right)\right.}}$

$r_{x y}=\frac{96 \cdot(26587)-(402) \cdot(6330)}{\sqrt{\left(96.1752-(402)^{2} \cdot\left(96.418980-(6330)^{2}\right)\right.}}$

$r_{x y}=\frac{2552352-2544660}{\sqrt{(168192-161604) \cdot(40222080-40068900)}}$

$r_{x y}=\frac{7692}{\sqrt{(6588) \cdot(153180)}}$

$$
\begin{aligned}
& r_{x y}=\frac{7692}{\sqrt{1009149840}} \\
& r_{x y}=\frac{7692}{31767.1} \\
& r_{x y}=0,242 \\
& \mathrm{r}_{\mathrm{xy}}=0,242 \text { dan seterusnya sampai butir }
\end{aligned}
$$

Selanjutnya nilai $r_{x y}$ dibandingkan dengan $r_{\text {tabel }}$ dengan taraf signifikan 5\%.

Kriteria keputusan :

- $\quad$ Valid $=r_{\text {hitung }}>r_{\text {tabel }}$ taraf signifikan $5 \%$

- Tidak valid $=\mathrm{r}_{\text {hitung }}<\mathrm{r}_{\text {tabel }}$ taraf signifikan 5\% Sedangkan $r_{\text {tabel }}$ dicari dengan menggunakan rumus sebagai berikut

$$
r_{\text {tabel }}=r(\alpha: \mathrm{n}-2)
$$

Diketahui :

$$
\begin{aligned}
\boldsymbol{r}_{\text {tabel }} & =\boldsymbol{r}(\boldsymbol{\alpha}: \mathbf{n}-\mathbf{2}) \\
\alpha & =5 \%(0,05) \\
\mathrm{n} & =96 \\
\mathrm{r}_{\text {tabel }} & =\mathrm{r}(\alpha: \mathrm{n}-2) \\
& =(0,05: 96-2) \\
& =0,201
\end{aligned}
$$

Dengan demikian, karena $r$ hasil perhitungan $r_{\text {hitung }}>r_{\text {tabel }}(0,242>0,201)$, sehingga disimpulkan bahwa butir pernyataan pada instrumen No. 1 variabel ekuitas merek dapat dikatakan valid.

\begin{tabular}{|c|c|c|c|}
\hline \multicolumn{4}{|c|}{ Tabel Hasil Validitas Instrumen Ekuitas Merek (X) } \\
\multicolumn{5}{|c|}{ Butir Instrumen } & $\mathbf{r}_{\text {htung }}$ & $\mathbf{r}_{\text {tabel }}$ & Keterangan \\
\hline 1 & 0.2420 & 0.2010 & Valid \\
\hline 2 & 0.2020 & 0.2010 & Valid \\
\hline 3 & 0.4870 & 0.2010 & Valid \\
\hline 4 & 0.4330 & 0.2010 & Valid \\
\hline 5 & 0.2260 & 0.2010 & Valid \\
\hline 6 & 0.2570 & 0.2010 & Valid \\
\hline 7 & 0.4550 & 0.2010 & Valid \\
\hline 8 & 0.2020 & 0.2010 & Valid \\
\hline 9 & 0.2570 & 0.2010 & Valid \\
\hline 10 & 0.2890 & 0.2010 & Valid \\
\hline 11 & 0.4750 & 0.2010 & Valid \\
\hline 12 & 0.5170 & 0.2010 & Valid \\
\hline 13 & 0.3590 & 0.2010 & Valid \\
\hline 14 & 0.5420 & 0.2010 & Valid \\
\hline 15 & 0.4130 & 0.2010 & Valid \\
\hline & & Sumber: Data olahan kuesioner, 2017 \\
\hline
\end{tabular}

\section{b. Variabel Y (Keputusan Pembelian)}

Berdasarkan data olahan, diketahui bahwa:

$\mathrm{n} \quad=96$ 


$$
\begin{aligned}
\sum \mathrm{Yi} & =414 \\
\sum \mathrm{Yt} & =6.092 \\
\sum \mathrm{Yi} . \mathrm{Yt} & =26.357 \\
\sum \mathrm{Yi}^{2} & =1.842 \\
\sum \mathrm{Yt}^{2} & =389.016
\end{aligned}
$$

$$
r_{x y}=\frac{n \cdot\left(\sum Y Y t\right)-\left(\sum Y\right) \cdot\left(\sum Y t\right)}{\sqrt{\left(n \cdot \sum Y^{2}-\left(\sum Y\right)^{2} \cdot\left(n \cdot \sum Y t^{2}-\left(\sum Y t\right)^{2}\right)\right.}}
$$$$
r_{x y}=\frac{n \cdot(\Sigma Y Y t)-(\Sigma Y) \cdot(\Sigma Y t)}{\sqrt{\left(n \cdot \Sigma Y^{2}-(\Sigma Y)^{2} \cdot\left(n \cdot \Sigma Y t^{2}-(\Sigma Y t)^{2}\right)\right.}}
$$$$
r_{x y}=\frac{96 .(26357)-(414) \cdot(6092)}{\sqrt{\left(96.1842-(414)^{2} \cdot\left(96.389016-(6092)^{2}\right)\right.}}
$$$$
r_{x y}=\frac{2530272-2522088}{\sqrt{(176832-171396) \cdot(37345536-37112464)}}
$$$$
r_{x y}=\frac{8184}{\sqrt{(5436) \cdot(233072)}}
$$$$
r_{x y}=\frac{8184}{\sqrt{1266979392}}
$$$$
r_{x y}=\frac{8184}{35594.7}
$$$$
r_{x y}=0,230
$$$$
r_{\mathrm{xy}}=0,230 \text { dan seterusnya sampai butir }
$$
pertanyaan ke - 15

Selanjutnya nilai $r_{x y}$ dibandingkan dengan rtabel dengan taraf signifikan 5\%.

Kriteria keputusan :

- $\quad$ Valid $=\mathrm{r}_{\text {hitung }}>\mathrm{r}_{\text {tabel }}$, taraf signifikan 5\%

- $\quad$ Tidak valid $=\mathrm{r}_{\text {hitung }}<\mathrm{r}_{\text {tabel }}$ taraf signifikan $5 \%$

Sedangkan $\mathrm{r}_{\text {tabel }}$ di cari dengan menggunakan rumus sebagai berikut :

$\mathrm{r}_{\text {tabel }}=\mathrm{r}(\alpha: \mathrm{n}-2)$

Diketahui :

$$
\begin{aligned}
\mathbf{r}_{\text {tabel }} & =\mathbf{r}(\boldsymbol{\alpha}: \mathbf{n}-\mathbf{2}) \\
\boldsymbol{\alpha} & =5 \%(0,05) \\
\mathrm{n} & =96 \\
\mathrm{r}_{\text {tabel }} & =\mathrm{r}(\boldsymbol{\alpha}: \mathrm{n}-2) \\
& =(0,05: 96-2) \\
& =0,201
\end{aligned}
$$

Dengan demikian, karena $r$ hasil perhitungan $\mathrm{r}_{\text {hitung }}>\mathrm{r}_{\text {tabel }}(0,230>0,201)$ sehingga disimpulkan bahwa butir pernyataan pada instrumen No. 1 variabel kinerja dapat dikatakan valid.

\begin{tabular}{c|c|c|c|}
\hline \multicolumn{4}{|c|}{ Variabel $\mathbf{Y}$} \\
Tabel Hasil Validitas Instrumen Keputusan Pembelian (Y) \\
Butir Instrumen & $\mathrm{r}_{\text {httung }}$ & $\mathbf{r}_{\text {tobel }}$ & Keterangan \\
\hline 1 & 0.2300 & 0.2010 & Valid \\
\hline 2 & 0.3640 & 0.2010 & Valid \\
\hline 3 & 0.3700 & 0.2010 & Valid \\
\hline
\end{tabular}

\begin{tabular}{|c|c|c|c|}
\hline 4 & 0.3560 & 0.2010 & Valid \\
\hline 5 & 0.4220 & 0.2010 & Valid \\
\hline 6 & 0.3880 & 0.2010 & Valid \\
\hline 7 & 0.3060 & 0.2010 & Valid \\
\hline 8 & 0.4860 & 0.2010 & Valid \\
\hline 9 & 0.4350 & 0.2010 & Valid \\
\hline 10 & 0.2840 & 0.2010 & Valid \\
\hline 11 & 0.3230 & 0.2010 & Valid \\
\hline 12 & 0.5250 & 0.2010 & Valid \\
\hline 13 & 0.5760 & 0.2010 & Valid \\
\hline 14 & 0.5010 & 0.2010 & Valid \\
\hline 15 & 0.2300 & 0.2010 & Valid \\
\hline & \multicolumn{3}{|c|}{ Sumber: Data olahan kuesioner, 2017 } \\
\hline
\end{tabular}

\section{Hasil Uji Reliabilitas}

a. Hasil Uji Reliabilitas Variabel (X) Ekuitas Merek

Metode yang digunakan dalam penelitian ini untuk menghitung reliabilitas instrumen yaitu dengan menggunakan metode Croncbach Alpha. Di mana rumus yang digunakan adalah sebagai berikut:

$$
r_{c a}=\left(\frac{\mathrm{k}}{\mathrm{k}-1}\right)\left(1-\frac{\sum \mathrm{Si}}{\mathrm{St}}\right)
$$

Langkah-langkah mencari nilai reliabilitas dengan metode Cronchbach Alpha adalah sebagai berikut :

1. Mencari varian butir

Variabel (X) ekuitas merek diketahui :

$$
\begin{aligned}
\sum^{Y i 2} & =1752 \\
\sum^{Y i} & =402 \\
\mathrm{n} & =96
\end{aligned}
$$

Maka:

$$
\mathrm{Si}=\frac{\sum x i^{2}-\frac{\left(\sum x i\right)^{2}}{n}}{n}
$$

$$
\begin{aligned}
& \mathrm{Si}=\frac{\sum x i^{2}-\frac{\left(\sum x i\right)^{2}}{n}}{n} \\
& \mathrm{Si}=\frac{1752-\frac{(402)^{2}}{96}}{96} \\
& \mathrm{Si}=\frac{1752-\frac{161604}{96}}{96} \\
& \mathrm{Si}=\frac{1752-1683.4}{96} \\
& \mathrm{Si}=\frac{68.6}{96}
\end{aligned}
$$

$\mathrm{Si}=0.715$ 
Varians butir ke-2 sampai ke-15 dapat dihitung dengan cara yang sama seperti menghitung varians yang pertama. Dengan demikian total varians butir adalah $\Sigma \mathrm{Si}=8.577$

2. Menghitung varians total

$$
\begin{aligned}
\sum \mathrm{xt}^{2} & =418980 \\
\sum \mathrm{x} t & =6330
\end{aligned}
$$$$
\mathrm{n}=96
$$

Maka :

$$
\begin{aligned}
& \text { St }=\frac{\sum x t^{2}-\frac{\left(\sum x t\right)^{2}}{n}}{n} \\
& \text { St }=\frac{\sum x t^{2}-\frac{\left(\sum x t\right)^{2}}{n}}{n} \\
& \text { St }=\frac{418980-\frac{(6330)^{2}}{96}}{96} \\
& \text { St }=\frac{418980-417384.37}{96} \\
& \text { St }=\frac{1595.63}{96} \\
& \text { St }=16.621
\end{aligned}
$$

3. Menghitung Reliabilitas

Diketahui :

$\mathrm{k}=10$

$\sum \mathrm{Si}=8.577$

$\sum$ St $=16.621$

$$
r_{c a}=\left(\frac{\mathrm{k}}{\mathrm{k}-1}\right)\left(1-\frac{\sum \mathrm{Si}}{\mathrm{St}}\right)
$$

$r_{c a}=\left(\frac{\mathrm{k}}{\mathrm{k}-1}\right)\left(\frac{\sum \mathrm{Si}}{\mathrm{St}}\right)$

$r_{c a}=\left(\frac{10}{10-1}\right)\left(1-\frac{8.577}{16.621}\right)$

$r_{c a}=0,538$

Kriteria keputusan

- $\quad r_{c a}>r_{\text {tabel }}(\alpha=0,05)$, maka instrumen (alat ukur) reliable.

- $r_{c a}<r_{\text {tabel }}(\alpha=0,05)$, maka instrumen (alat ukur) tidak reliable.

Dengan demikian, karena hasil perhitungan $r_{c a}$ lebih besar dari $r_{\text {tabel }}(0,538>0,201)$ sehingga instrumen penelitian dapat dikatakan reliable.

\section{b. Hasil Uji Realibilitas Variabel (Y) \\ Keputusan Pembelian}

Metode yang digunakan dalam penelitian ini untuk menghitung reliabilitas instrumen yaitu dengan menggunakan metode Croncbach Alpha. Di mana rumus yang digunakan adalah sebagai berikut :

$$
\begin{aligned}
& r_{c a}=\left(\frac{\mathrm{k}}{\mathrm{k}-1}\right)\left(1-\frac{\sum \mathrm{Si}}{\mathrm{St}}\right) \\
& r_{c a}=\left(\frac{\mathrm{k}}{\mathrm{k}-1}\right)\left(1-\frac{\sum \mathrm{Si}}{\mathrm{St}}\right)
\end{aligned}
$$

Langkah-langkah mencari nilai reliabilitas dengan metode Cronchbach Alpha adalah sebagai berikut :

1. Mencari varian butir

Variabel (Y) Kinerja diketahui :

$$
\begin{aligned}
\sum^{Y i 2} & =1842 \\
\sum \mathrm{Yi} & =414 \\
\mathrm{n} & =96
\end{aligned}
$$

Maka :

$$
\mathrm{Si}=\frac{\sum Y i^{2}-\frac{\left(\sum Y i\right)^{2}}{n}}{n}
$$

$\mathrm{Si}=\frac{\sum Y i^{2}-\frac{\left(\Gamma^{Y i)^{2}}\right.}{n}}{n}$

$\mathrm{Si}=\frac{1842-\frac{(414)^{2}}{96}}{96}$

$\mathrm{Si}=\frac{1842-\frac{171396}{96}}{96}$

$\mathrm{Si}=\frac{1842-1785.37}{96}$

$\mathrm{Si}=\frac{56.63}{96}$

$\mathrm{Si}=0.590$

Varians butir ke-2 sampai ke-15 dapat dihitung dengan cara yang sama seperti menghitung varians yang pertama. Dengan demikian total varians butir adalah $\Sigma \mathrm{Si}=11.111$

2. Menghitung varians total

$$
\begin{aligned}
\sum \mathrm{Yt}^{2} & =389016 \\
\sum \mathrm{Yt} & =6092 \\
\mathrm{n} & =96
\end{aligned}
$$

Maka :

$$
\mathrm{St}=\frac{\sum y t^{2}-\frac{\left(\sum y t\right)^{2}}{n}}{n}
$$




$$
\begin{aligned}
& \mathrm{St}=\frac{\sum y t^{2}-\frac{\left(\sum y t\right)^{2}}{n}}{n} \\
& \mathrm{St}=\frac{389016-\frac{(6092)^{2}}{96}}{96} \\
& \mathrm{St}=\frac{389016-386588.17}{96} \\
& \mathrm{St}=\frac{2472.83}{96} \\
& \mathrm{St}=25.29
\end{aligned}
$$

3. Menghitung Reliabilitas

Diketahui :

$\mathrm{k}=15$

$\sum$ si $=11.111$

$\sum$ st $=25.29$

$$
r_{c a}=\left(\frac{\mathrm{k}}{\mathrm{k}-1}\right)\left(1-\frac{\sum \mathrm{Si}}{\mathrm{St}}\right)
$$$$
r_{c a}=\left(\frac{\mathrm{k}}{\mathrm{k}-1}\right)\left(1-\frac{\sum \mathrm{Si}}{\mathrm{St}}\right)
$$

$r_{c a}=\left(\frac{10}{10-1}\right)\left(1-\frac{11.111}{25.29}\right)$

$r_{c a}=0,623$

Kriteria keputusan

- $\mathrm{r}_{\mathrm{ca}}>\mathrm{r}_{\text {tabel }}(\alpha=0,05)$, maka instrumen (alat ukur) reliable

- $\mathrm{r}_{\mathrm{ca}}<\mathrm{r}_{\text {tabel }}(\alpha=0,05)$, maka instrumen (alat ukur) tidak reliable

Dengan demikian, karena hasil perhitungan $r_{\text {ca }}$ lebih besar daripada $r_{\text {tabel }}(0,623>0,201)$ sehingga instrumen penelitian dapat dikatakan reliable.

\section{Uji Koefisien Korelasi}

Dalam menganalisis pengaruh Ekuitas Merek (X) terhadap Keputusan Pembelian (Y) pada Komunitas MI Fans Indonesia, digunakan metode korelasi sederhana. Rumus yang digunakan untuk menghitung korelasi antara variabel bebas (X) dengan variabel terikat (Y) adalah korelasi product moment.

Adapun rumus uji korelasi sederhana adalah:

$$
r_{x y}=\frac{n \cdot\left(\sum X Y\right)-\left(\sum X\right) \cdot\left(\sum Y\right)}{\sqrt{\left(n \cdot \sum X^{2}-\left(\sum X\right)^{2} \cdot\left(n \cdot \sum Y^{2}-\left(\sum Y\right)^{2}\right)\right.}}
$$

$r_{x y}=\frac{n \cdot\left(\sum X Y\right)-\left(\sum X\right) \cdot\left(\sum Y\right)}{\sqrt{\left(n \cdot \sum X^{2}-\left(\sum X\right)^{2} \cdot\left(n \cdot \sum Y^{2}-\left(\sum Y\right)^{2}\right)\right.}}$

Di mana :

$\mathrm{r}_{\mathrm{xy}}=$ Koefisien korelasi

$\mathrm{n}=$ Jumlah responden

\begin{tabular}{|c|c|c|c|c|c|}
\hline \multicolumn{6}{|c|}{ Tabel Data Korelasi Product Moment } \\
\hline No & $x$ & $Y$ & X2 & Y2 & X.Y \\
\hline 1 & 70 & 70 & 4900 & 4900 & 4900 \\
\hline 2 & 68 & 65 & 4624 & 4225 & 4420 \\
\hline 3 & 68 & 70 & 4624 & 4900 & 4760 \\
\hline 4 & 70 & 66 & 4900 & 4356 & 4620 \\
\hline 5 & 70 & 70 & 4900 & 4900 & 4900 \\
\hline 6 & 68 & 68 & 4624 & 4624 & 4624 \\
\hline 7 & 70 & 70 & 4900 & 4900 & 4900 \\
\hline 8 & 65 & 70 & 4225 & 4900 & 4550 \\
\hline 9 & 70 & 66 & 4900 & 4356 & 4620 \\
\hline 10 & 70 & 70 & 4900 & 4900 & 4900 \\
\hline 11 & 69 & 65 & 4761 & 4225 & 4485 \\
\hline 12 & 70 & 70 & 4900 & 4900 & 4900 \\
\hline 13 & 70 & 69 & 4900 & 4761 & 4830 \\
\hline 14 & 67 & 70 & 4489 & 4900 & 4690 \\
\hline 15 & 70 & 64 & 4900 & 4096 & 4480 \\
\hline 16 & 70 & 65 & 4900 & 4225 & 4550 \\
\hline 17 & 65 & 69 & 4225 & 4761 & 4485 \\
\hline 18 & 68 & 65 & 4624 & 4225 & 4420 \\
\hline 19 & 70 & 60 & 4900 & 3600 & 4200 \\
\hline 20 & 65 & 68 & 4225 & 4624 & 4420 \\
\hline 21 & 70 & 60 & 4900 & 3600 & 4200 \\
\hline 22 & 72 & 70 & 5184 & 4900 & 5040 \\
\hline 23 & 67 & 65 & 4489 & 4225 & 4355 \\
\hline 24 & 60 & 56 & 3600 & 3136 & 3360 \\
\hline 25 & 65 & 65 & 4225 & 4225 & 4225 \\
\hline 26 & 65 & 56 & 4225 & 3136 & 3640 \\
\hline 27 & 70 & 55 & 4900 & 3025 & 3850 \\
\hline 28 & 58 & 62 & 3364 & 3844 & 3596 \\
\hline 29 & 59 & 60 & 3481 & 3600 & 3540 \\
\hline 30 & 65 & 58 & 4225 & 3364 & 3770 \\
\hline 31 & 60 & 50 & 3600 & 2500 & 3000 \\
\hline 32 & 56 & 59 & 3136 & 3481 & 3304 \\
\hline 33 & 62 & 60 & 3844 & 3600 & 3720 \\
\hline 34 & 62 & 53 & 3844 & 2809 & 3286 \\
\hline 35 & 63 & 60 & 3969 & 3600 & 3780 \\
\hline 36 & 69 & 57 & 4761 & 3249 & 3933 \\
\hline 37 & 67 & 58 & 4489 & 3364 & 3886 \\
\hline 38 & 60 & 55 & 3600 & 3025 & 3300 \\
\hline 39 & 57 & 68 & 3249 & 4624 & 3876 \\
\hline 40 & 70 & 65 & 4900 & 4225 & 4550 \\
\hline 41 & 67 & 55 & 4489 & 3025 & 3685 \\
\hline 42 & 52 & 58 & 2704 & 3364 & 3016 \\
\hline 43 & 56 & 58 & 3136 & 3364 & 3248 \\
\hline
\end{tabular}

$\sum \mathrm{X}=$ Jumlah total variabel $\mathrm{X}$
$\Sigma \mathrm{Y}=$ Jumlah total variabel $\mathrm{Y}$

$\Sigma \mathrm{XY}=$ Jumlah total perkalian variabel $\mathrm{X}$ dan Y

$\Sigma \mathrm{X}^{2}=$ Jumlah total kuadrat variabel $\mathrm{X}$

$\Sigma \mathrm{Y}^{2}=$ Jumlah total kuadrat variabel $\mathrm{Y}$ 
JURNAL MADANI: Ilmu Pengetahuan, Teknologi, dan Humaniora, Vol. 2, No. 1, Maret 2019: 147 - 161

\begin{tabular}{|c|c|c|c|c|c|}
\hline 44 & 65 & 68 & 4225 & 4624 & 4420 \\
\hline 45 & 61 & 65 & 3721 & 4225 & 3965 \\
\hline 46 & 67 & 59 & 4489 & 3481 & 3953 \\
\hline 47 & 61 & 53 & 3721 & 2809 & 3233 \\
\hline 48 & 61 & 55 & 3721 & 3025 & 3355 \\
\hline 49 & 67 & 63 & 4489 & 3969 & 4221 \\
\hline 50 & 63 & 60 & 3969 & 3600 & 3780 \\
\hline 51 & 67 & 66 & 4489 & 4356 & 4422 \\
\hline 52 & 68 & 63 & 4624 & 3969 & 4284 \\
\hline 53 & 65 & 62 & 4225 & 3844 & 4030 \\
\hline 54 & 67 & 61 & 4489 & 3721 & 4087 \\
\hline 55 & 66 & 65 & 4356 & 4225 & 4290 \\
\hline 56 & 65 & 70 & 4225 & 4900 & 4550 \\
\hline 57 & 61 & 68 & 3721 & 4624 & 4148 \\
\hline 58 & 67 & 68 & 4489 & 4624 & 4556 \\
\hline 59 & 61 & 67 & 3721 & 4489 & 4087 \\
\hline 60 & 68 & 65 & 4624 & 4225 & 4420 \\
\hline 61 & 64 & 66 & 4096 & 4356 & 4224 \\
\hline 62 & 61 & 66 & 3721 & 4356 & 4026 \\
\hline 63 & 61 & 60 & 3721 & 3600 & 3660 \\
\hline 64 & 61 & 61 & 3721 & 3721 & 3721 \\
\hline 65 & 67 & 62 & 4489 & 3844 & 4154 \\
\hline 66 & 65 & 62 & 4225 & 3844 & 4030 \\
\hline 67 & 68 & 65 & 4624 & 4225 & 4420 \\
\hline 68 & 68 & 65 & 4624 & 4225 & 4420 \\
\hline 69 & 65 & 65 & 4225 & 4225 & 4225 \\
\hline 70 & 60 & 65 & 3600 & 4225 & 3900 \\
\hline 71 & 70 & 62 & 4900 & 3844 & 4340 \\
\hline 72 & 64 & 68 & 4096 & 4624 & 4352 \\
\hline 73 & 62 & 63 & 3844 & 3969 & 3906 \\
\hline 74 & 61 & 65 & 3721 & 4225 & 3965 \\
\hline 75 & 70 & 64 & 4900 & 4096 & 4480 \\
\hline 76 & 69 & 60 & 4761 & 3600 & 4140 \\
\hline 77 & 70 & 67 & 4900 & 4489 & 4690 \\
\hline 78 & 70 & 70 & 4900 & 4900 & 4900 \\
\hline 79 & 70 & 66 & 4900 & 4356 & 4620 \\
\hline 80 & 70 & 65 & 4900 & 4225 & 4550 \\
\hline 81 & 68 & 70 & 4624 & 4900 & 4760 \\
\hline 82 & 70 & 66 & 4900 & 4356 & 4620 \\
\hline 83 & 64 & 70 & 4096 & 4900 & 4480 \\
\hline 84 & 69 & 64 & 4761 & 4096 & 4416 \\
\hline 85 & 68 & 70 & 4624 & 4900 & 4760 \\
\hline 86 & 70 & 67 & 4900 & 4489 & 4690 \\
\hline 87 & 68 & 70 & 4624 & 4900 & 4760 \\
\hline 88 & 66 & 70 & 4356 & 4900 & 4620 \\
\hline 89 & 70 & 66 & 4900 & 4356 & 4620 \\
\hline 90 & 68 & 65 & 4624 & 4225 & 4420 \\
\hline 91 & 66 & 65 & 4356 & 4225 & 4290 \\
\hline 92 & 70 & 67 & 4900 & 4489 & 4690 \\
\hline 93 & 65 & 65 & 4225 & 4225 & 4225 \\
\hline 94 & 71 & 67 & 5041 & 4489 & 4757 \\
\hline
\end{tabular}

\begin{tabular}{|c|c|c|c|c|c|}
\hline 95 & 68 & 65 & 4624 & 4225 & 4420 \\
\hline 96 & 68 & 62 & 4624 & 3844 & 4216 \\
\hline$\Sigma$ & 6330 & 6147 & 418980 & 395741 & 406082 \\
\hline \multicolumn{5}{|c|}{ sumber: Data diolah, 2017 } \\
\hline
\end{tabular}

Diketahui :

$\mathrm{n}=96$

$\Sigma \mathrm{X}=6330$

$\sum \mathrm{Y}=6147$

$\sum \mathrm{X}^{2}=418980$

$\sum Y^{2}=395741$

$\Sigma X Y=406082$

$r_{x y}=\frac{n \cdot\left(\sum X Y\right)-\left(\sum X\right) \cdot\left(\sum Y\right)}{\sqrt{\left(n \cdot \sum X^{2}-\left(\sum X\right)^{2} \cdot\left(n \cdot \sum Y^{2}-\left(\sum Y\right)^{2}\right)\right.}}$

$$
r_{x y}=\frac{n \cdot\left(\sum X Y\right)-\left(\sum X\right) \cdot\left(\sum Y\right)}{\sqrt{\left(n \cdot \sum X^{2}-\left(\sum X\right)^{2} \cdot\left(n \cdot \sum Y^{2}-\left(\sum Y\right)^{2}\right)\right.}}
$$

$r_{x y}=\frac{96 .(406082)-(6330) \cdot(6147)}{\sqrt{\left(96.418980-(6330)^{2} \cdot\left(96.395741-(6147)^{2}\right)\right.}}$

$r_{x y}=\frac{38983872-38910510}{\sqrt{(40222080-40068900) \cdot(37991136-37785609)}}$

$r_{x y}=\frac{73362}{\sqrt{(153180) \cdot(205527)}}$

$r_{x y}=\frac{73362}{\sqrt{31482625860}}$

$r_{x y}=\frac{73362}{177433.44}$

$r_{x y}=0,41346$

Tabel Pedoman Untuk Memberikan

Interpretasi Koefisien Korelasi

\begin{tabular}{|c|c|}
\hline Interval Koefisien & Tingkat Hubungan \\
\hline $0.00-0,199$ & Sangat lemah \\
\hline $0.20-0,399$ & Lemah \\
\hline $0.40-0,599$ & Cukup Kuat \\
\hline $0.60-0,799$ & Kuat \\
\hline $0.80-1,000$ & Sangat Kuat \\
\hline & Sumber: Sugiono (2016:184) \\
\hline
\end{tabular}

Dari hasil perhitungan menggunakan rumus koefisien korelasi ada pengaruh positif antara ekuitas merek dengan keputusan pembelian yaitu sebesar $r=0,41346$ yang termasuk kategori Cukup Kuat.

\section{Analisis Koefisien Determinasi}

Setelah mengetahui nilai koefisien korelasi $\left(r_{\mathrm{rY}}\right)$ antara variabel $\mathrm{X}$ dan variabel $\mathrm{Y}$, selanjutnya dilakukan analisis koefisien determinasi. Tujuan analisis koefisien determinasi dalam penelitian ini adalah untuk mengetahui besarnya kontribusi variabel X (Ekuitas Merek) terhadap variabel Y (Keputusan Pembelian) dalam (\%). Rumus yang 
digunakan dalam analisis koefisien determinasi adalah sebagai berikut :

$\mathrm{KD}$ ( Koefisien Determinasi $)=\mathrm{r}_{\mathrm{xy}}{ }^{2} \times 100 \%$

$$
\begin{aligned}
& =(0,41346)^{2} \times 100 \% \\
& =0,1709 \times 100 \% \\
& =17,09 \%
\end{aligned}
$$

Hal ini membuktikan bahwa besarnya pengaruh Ekuitas Merek terhadap Keputusan Pembelian sebesar 17,09\%. Sedangkan sisanya sebesar $82,1 \%$ dipengaruhi beberapa faktor lainnya yang tidak diteliti.

\section{Uji Regresi Linier Sederhana}

Dalam penelitian ini analisis regresi linier bertujuan untuk mengetahui seberapa besar pengaruh Ekuitas Merek terhadap Keputusan Pembelian. Salah satu model yang paling mudah untuk menjelaskan pengaruh itu adalah regresi linier sederhana, yaitu :

$$
\mathbf{Y}=\mathbf{a}+\mathbf{b} \mathbf{x}
$$

Diketahui :

$$
\begin{aligned}
\sum X & =6330 \\
\Sigma Y & =6147 \\
n & =96 \\
\sum X^{2} & =418980 \\
\Sigma X Y & =406082
\end{aligned}
$$

a. Mencari nilai b :

$$
\begin{aligned}
& b=\frac{N \cdot \sum X Y-\left(\sum X\right)\left(\sum Y\right)}{N\left(\sum X^{2}\right)-\left(\sum X\right)^{2}} \\
& b=\frac{96.406082-(6330)(6147)}{96(418980)-(6330)^{2}} \\
& b=\frac{38983872-38910510}{40222080-40068900} \\
& b=\frac{73362}{153180} \\
& b=0,479
\end{aligned}
$$

b. Mencari nilai a :

$$
\begin{aligned}
& a=\frac{\sum Y-b \sum X}{n} \\
& a=\frac{6147-0,479(6330)}{96} \\
& a=\frac{6147-3032,07}{96}
\end{aligned}
$$

$$
\begin{aligned}
& a=\frac{3114,93}{96} \\
& a=32,447
\end{aligned}
$$

Regresi linier sederhana diperoleh dari persamaaan :

\section{$\mathrm{Y}=32,447+0,479 \mathrm{x}$.}

Artinya apabila variabel Ekuitas Merek meningkat 1 satuan maka akan meningkatkan keputusan pembelian sebesar 0,479. Sebaliknya apabila Ekuitas Merek diturunkan sebesar 1 satuan maka akan terjadi penurunan keputusan pembelian sebesar 0,479 .

\section{Uji Signifikan}

Berdasarkan hasil perhitungan di atas, maka dilakukan pengujian hipotesa dengan cara membandingkan nilai ttabel dengan $t_{\text {hitung }}$. Nilai $\mathrm{t}_{\text {tabel }}$ ditentukan berdasarkan tingkat signifikan ( $\alpha$ ) yang digunakan dan derajat kebebasan $(\mathrm{df}=\mathrm{n}-2)$ yang besarnya tergantung dari jumlah sampel (n). Taraf nyata yang digunakan sebesar 0,05 (5\%).

Rumus $\mathrm{t}_{\text {hitung }}$ adalah sebagai berikut :

$$
\begin{aligned}
& \mathrm{t}_{\text {hitung }}=\frac{r_{x y} \sqrt{n-2}}{\sqrt{1-r_{x y^{2}}}} \\
& \mathrm{t}_{\text {hitung }}=\frac{r_{x y} \sqrt{n-2}}{\sqrt{1-r_{x y^{2}}}}
\end{aligned}
$$

a. Menguji signifikansi

$$
t_{\text {hitung }}=\frac{r_{x y} \sqrt{n-2}}{\sqrt{1-r_{x y^{2}}}}
$$

$$
\begin{array}{ll}
\mathrm{t}_{\text {hitung }} & =\frac{r_{x y} \sqrt{n-2}}{\sqrt{1-r_{x y^{2}}}} \\
\mathrm{t}_{\text {hitung }} & =\frac{0,41346 \sqrt{96-2}}{1-(0,41346)^{2}} \\
\mathrm{t}_{\text {hitung }} & =\frac{0,41346 \sqrt{94}}{1-0,1709} \\
\mathrm{t}_{\text {hitung }} & =\frac{4,0086}{0,8291} \\
\mathrm{t}_{\text {hitung }} & =4,8349
\end{array}
$$

b. Tingkat signifikan

$$
\text { Mencari } \mathrm{t}_{\text {tabel }} \text { (dua sisi) }
$$

$$
\begin{aligned}
\mathbf{t}_{\text {tabel }} & =(\boldsymbol{\alpha}: \mathbf{n}-\mathbf{2}) \\
\mathrm{t}_{\text {tabel }} & =(\boldsymbol{\alpha}: \mathbf{n}-2) \\
\mathrm{t}_{\text {tabel }} & =(0,05: 96-2) \\
\mathrm{t}_{\text {tabel }} & =(0,05: 94)
\end{aligned}
$$


$\mathrm{t}_{\text {tabel }}=1,986$

Kriteria Pengambilan keputusan :

- $\quad \mathrm{t}_{\text {hitung }}>\mathrm{t}_{\text {tabel }}(\alpha=5 \%, \mathrm{df}=\mathrm{n}-2)$, maka $\mathrm{H}_{0}$ di tolak dan Haditerima

- $\mathrm{t}_{\text {hitung }}<\mathrm{t}_{\text {tabel }}(\alpha=5 \%, \mathrm{df}=\mathrm{n}-2)$, maka $\mathrm{H}_{0}$ di terima dan $\mathrm{H}_{\mathrm{a}}$ ditolak

Dengan demikian, karena $\mathrm{t}_{\text {hitung }}$ lebih besar daripada $\mathrm{t}_{\text {tabel }}(4,8349>1,986)$, maka $\mathrm{H}_{0}$ di tolak dan $\mathrm{H}_{\mathrm{a}}$ diterima. Hal itu berarti Ekuitas Merek (X) mempunyai pengaruh yang signifikan terhadap tingkat Keputusan Pembelian di Komunitas MI Fans Jakarta dan Depok.

\section{Pembahasan}

Dari hasil pengujian statistik dan analisis di atas, maka dapaat dipaparkan analisis pengaruh ekuitas merek terhadap keputusan pembelian Handphone Xiaomi (Studi Kasus Komunitas Mi Fans Jakarta dan Depok), sebagai berikut :

\section{Ekuitas Merek Pada Handphone Xiaomi}

Dari hasil perhitungan uji validitas instrumen menggunakan rumus Korelasi Pearson Product Moment untuk variabel X (Ekuitas Merek) dapat dikatakan valid karena $\mathrm{r}_{\text {hitung }}$ lebih besar daripada $r_{\text {tabel }}(0,242>0,201)$.

Dari hasil perhitungan uji reliabilitas instrumen dengan menggunakan metode Cronchbach Alpha untuk variabel X (Keputusan Pembelian) dapat dikatakan reliable karena hasil perhitungan $r_{c a}$ lebih besar dari pada $r_{\text {tabel }}(0,538>0,201)$.

\section{Keputusan Pembelian Pada Komunitas MI Fans Jakarta Dan Depok}

Dari hasil perhitungan uji validitas instrumen menggunakan rumus Korelasi Pearson Product Moment untuk variabel Y (Keputusan Pembelian) dapat dikatakan valid karena $r_{\text {hitung }}$ lebih besar daripada $\mathrm{r}_{\text {tabel }}(0,230>0,201)$.

Dari hasil perhitungan uji reliabilitas instrumen dengan menggunakan metode Cronchbach Alpha untuk variabel Y (Keputusan Pembelian) dapat dikatakan reliable karena hasil perhitungan $\mathrm{r}_{\mathrm{ca}}$ lebih besar dari pada $\mathrm{r}_{\text {tabel }}(0,625>0,201)$.

3. Pengaruh Ekuitas Merek Terhadap Keputusan Pembelian Handphone Xiaomi

Berdasarkan hasil perhitungan dari penelitian tersebut di atas maka dapat diberikan uji hipotesis sebagai berikut :

- $\quad \mathrm{H}_{0}$ ditolak dan Ha diterima, karena $\mathrm{t}_{\text {hitung }}>$ $\mathrm{t}_{\text {tabel }}(4,8349>1,986)$, artinya Ekuitas Merek (X) mempunyai pengaruh yang signifikan terhadap Keputusan Pembelian (Y).

- Dari hasil perhitungan menggunakan koefisien determinasi hasilnya adalah 17,09\%. Hal ini membuktikan bahwa besarnya pengaruh Ekuitas Merek terhadap Keputusan Pembelian sebesar 17,09\%. Sedangkan sisa- nya sebesar $82,1 \%$ dipengaruhi oleh beberapa faktor lainnya yang tidak termasuk dalam penelitian ini.

- Dari hasil perhitungan menggunakan rumus koefisien korelasi ada pengaruh positif antara Ekuitas Merek dengan Keputusan Pembelian yaitu sebesar $\mathrm{r}=0,41346$ yang termasuk kategori Cukup Kuat.

- Dari hasil perhitungan uji regresi linier sederhana diperoleh persamaaan $\mathrm{Y}=$ $32,447+0,479 x$. Artinya apabila variabel Ekuitas Merek meningkat 1 satuan maka akan meningkatkan Keputusan Pembelian sebesar 0,479. Sebaliknya, apabila Ekuitas Merek diturunkan sebesar 1 satuan maka akan terjadi penurunan Keputusan Pembelian sebesar 0,479 .

\section{SIMPULAN \\ Kesimpulan}

Adapun kesimpulan yang diambil berdasarkan hasil analisis dan pembahasan mengenai pengaruh Ekuitas Merek terhadap Keputusan Pembelian handphone Xiaomi, sebagai berikut :

1. Berdasarkan hasil perhitungan dengan menggunakan koefisien determinasi diperoleh hasil sebesar 17,09\%. Hal ini membuktikan bahwa besarnya pengaruh Ekuitas Merek terhadap Keputusan Pembelian sebesar 17,09\%. Sedangkan sisanya sebesar $82,1 \%$ dipengaruhi beberapa faktor lainnya yang tidak termasuk dalam penelitian ini. Dari pengujian Hipotesis $\mathrm{H}_{0}$ ditolak dan $\mathrm{H}_{\mathrm{a}}$ diterima, karena $\mathrm{t}_{\text {hitung }}>$ ttabel $(4,8349>1,986)$, artinya Ekuitas merek (X) mempunyai pengaruh yang signifikan terhadap Keputusan pembelian (Y).

2. Dari hasil perhitungan dengan menggunakan rumus koefisien korelasi terdapat pengaruh yang positif antara Ekuitas Merek dengan Keputusan Pembelian yaitu sebesar $r=0,41346$, sehingga termasuk kategori Cukup Kuat. Dari hasil perhitungan uji regresi linier sederhana diperoleh persamaaan $Y=32,447+0,479 x$. Artinya apabila variabel Ekuitas Merek meningkat 1 satuan maka akan meningkatkan Keputusan Pembelian sebesar 0,479. Sebaliknya apabila Ekuitas Merek diturunkan sebesar 1 satuan maka akan terjadi penurunan Keputusan Pembelian sebesar 0,479.

\section{Saran}

Untuk lebih meningkatkan konsumen dalam membeli handphone Xiaomi, beberapa hal yang perlu dilakukan yaitu :

1. Sesuai dengan hasil kuesioner variabel Ekuitas Merek, kondisi yang paling baik 
pada indikator penilaian merek. Jawaban responden yang masuk kriteria setuju dan sangat setuju sebanyak 2,75\%. Sedangkan kondisi indikator yang tidak baik adalah perasaan merek. Jawaban responden yang masuk kriteria setuju dan sangat setuju sebanyak $1.70 \%$. Untuk lebih baik lagi ke depannya, langkah yang harus diambil perusahaan dengan melakukan pendekatan emosional kepada konsumen. Salah satu yang bisa dilakukan aalah dengan menggelar melakukan event dan promosi agar respon konsumen terhadap merek akan terus terjaga dengan baik.

2. Berdasarkan hasil kuesioner variabel Keputusan Pembelian, kondisi yang paling baik terletak pada indikator pengenalan masalah. Adapun jawaban responden yang masuk kriteria setuju dan sangat setuju sebanyak 2.54\%. Sementara itu kondisi indikator yang tidak baik adalah pasca pembelian dengan jawaban responden yang masuk kriteria setuju dan sangat setuju sebanyak $2.31 \%$. Untuk lebih baik lagi ke depannya, langkah yang harus diambil perusahaan adalah secara terus-menerus melakukan inovasi baru pada produknya. Selain itu melaui peningkatan kualitas produk agar konsumen merasa puas pada saat membeli handphone Xiaomi.

\section{DAFTAR PUSTAKA}

Alex S Nitisemito. 2012. Manajemen Suatu Dasar dan Pengantar. Arena Ilmu. Jakarta.

Alma, Buchari. 2014. Manajemen Pemasaran dan Pemasaran Jasa. Penerbit Alfabeta. Bandung.

Arikunto, Suharsini. 2010. Prosedur Penelitian Suatu Pendekatan Praktek. Rineka Cipta. Jakarta.

Astute, Sri Wahjuni dan I Gede Cahyadi. 2007. Pengaruh Elemen Ekuitas Merek Terhadap Rasa Percaya Diri Pelanggan Di Surabaya Atas Keputusan Pembelian Sepeda Motor Honda. Majalah Ekonomi Tahun XVII. No. 2. Agustus. Hal. 145-156. Universitas Airlangga. Surabaya.

Budi, A. P. 2013. Manajemen Marketing Perhotelan. CV Andi Offset. Yogyakarta.

Daft, Richard L. 2012. Era Baru Manajemen, Terjemahan Tita Maria Kanita, Edisi ke 9, Buku 2. Salemba Empat. Jakarta.

Darmadi Durianto, Sugiarto, Lie Joko Budiman. 2004. Brand Equity Ten. PT Gramedia Pustaka Utama. Jakarta.

Daryanto. 2011. Manajemen Pemasaran. Sari Kuliah. Satu Nusa. Bandung.

Djaslim Saladin. 2012. Manajemen Pemasaran, Analisis Perencanaan Pelaksanaan, UnsurUnsur Pemasaran. CV Linda Karya. Bandung.
Hahn, Fred E. 2002. Beriklan dan Berpromosi Sendiri. PT Gramedia Putaka Utama. Jakarta.

Hasibuan, Malayu S.P. 2014. Manajemen Sumber Daya Manusia (Edisi Revisi). BumiAksara. Jakarta.

Istijanto. 2009. Aplikasi Praktis Riset Pemasaran. Gramedia Pustaka Utama. Jakarta.

Kasmir. 2004. Bank dan Lembaga Keuangan Lainnya Edisi Keenam. PT Raja Grafindo Persada. Jakarta.

Kevin Lane Keller. 2009. Strategic Brand Management. Pearson/Prentice Hall.

Knapp, Duanc E. 2001. The Brand Mindset. Penerbit Andi. Yogyakarta.

Kotler, Philip and Gary Armstrong. 2012. Prinsipprinsip Pemasaran. Edisi 13. Jilid 1. Erlangga. Jakarta.

Kotler dan Keller. 2009. Manajemen Pemasaran. Jilid I. Edisi Ke-13. Erlangga. Jakarta.

Kotler dan Keller. 2012. Marketing Management Edisi 14, Global Edition. Pearson Prentice Hall

Kotler, Philip. 2008. Manajemen Pemasaran, Dasar-Dasar Pemasarn Edisi 9 Jilid 1. PT. INDEKS Kelompok Gramedia. Jakarta.

Kotler, Philip. 2012. Manajemen Pemasaran. PT. INDEKS Kelompok Gramedia. Jakarta.

Kotler, Philip dan Gary Amstrong. 2008. Prinsipprinsip Pemasaran, Edisi 12. Erlangga. Jakata.

Kotler, Philip dan Keller. 2007. Manajemen Pemasaran, Jilid I, Edisi Kedua. PT Indeks. Jakarta.

Kotler, Philip dan Kevin Keller. 2011. Manajemen Pemasaran, Edisi 13 Jilid 1 dan 2. Erlangga. Jakarta.

Kotler, Philip dan Kevin Keller. 2012. Marketing Management, Edisi 14, Prentice-Hall Published. New Jersey.

Kurtz, David L. and Boone. 2012. Principles Of Conteremporary Marketing. Fifteen Edition. Cenbage Learning. USA.

Lamb, Hair, Mcdaniel. 2001. Pemasaran. Buku -1. PT Salemba Emban Raya. Jakarta.

Mudrajad Kuncoro, Ph.D. 2003. Metode Riset Untuk Bisnis \& Ekonomi. Erlangga. Jakarta.

Philip Kotler dan Kevin L. Keller. 2006. Manajemen Pemasaran Edisi Ke-12 Jilid Ke-1. Indeks. New Jersey.

Robbins, Stephen P. dan Coulter, Marry. 2010. Manajemen (Edisi Kesepuluh). Erlangga. Jakarta.

Setiadi, Nugroho J. 2010. Perilaku Konsumen. Cetakan 4. Edisi Revisi. Kencana. Jakarta.

Schiffman, LG dan Leslie Lazar Kanuk. 2010. Consumer Behavior Tenth Edition. Pearson Education.

Siregar, Sofyan. 2010. Statistika Deskriptif Untuk Penelitian. PT Rajagrafindo Persada. Jakarta.

Sugiyono. 2012. Metode Penelitian Bisnis. Alfabeta. 
Bandung.

Sugiyono. 2016. Metode Penilitian Kuantitatif

Kualitatif dan Kombinasi (Mixed Methods).

Alfabeta. Bandung.

Sugiyono. 2014. Metode Penelitian Pendidikan

Pendekatan Kuantitatif, Kualitatif, dan R\&D.

Alfabeta. Bandung.

Suharno \& Yudi Sutarso. 2010. Marketing In Practice. Graha Ilmu. Yogyakarta.

Swastha, Basu. 2010. Manajemen Penjualan: Pelaksanaan Penjualan. BPFE. Yogyakarta.

Tjiptono, Fandy dan Gregorius Chandra. 2012. Pemasaran Strategic. Andi. Yogyakarta.

William J. Stanton. 2004. Prinsip Pemasaran. Edisi Ketujuh Jilid Kesatu. Erlangga. Jakarta. 